\title{
THE RESULTS OF TREATMENT OF SLIPPED FEMORAL EPIPHYSIS
}

\author{
J. E. Hall, Toronto, Canada \\ From the Institute of Orthopaedics, Roval National Orthopaedic Hospital, London, England
}

!

In 1950 a sub-committee of the British Orthopaedic Association was formed under the direction of $\mathrm{Mr} \mathrm{H}$. Jackson Burrows and $\mathrm{Mr} \mathrm{E}$. N. Wardle for the study of slipped femoral epiphysis. A large number of surgeons filled in questionnaires about patients beginning treatment. A study of the early findings in one hundred of these patients forms the basis of a separate report, dealing principally with etiology and onset (Burrows 1957).

These patients, with the addition of thirty-eight others, have been observed for five years. The upper femoral epiphysis had slipped in 173 hips. All the patients have been interviewed and examined by the writer, who was able to peruse the old notes and radiographs in nearly every case.

Drawn from many centres, the material is heterogeneous and represents a random sample of the results in the United Kingdom in recent years.

\section{THE METHOD OF ASSESSMENT}

Shepherd's (1954) method of assessing the results of arthroplasties was adopted to classify the results of treatment of slipped femoral epiphysis, with the modifications necessary in much younger patients. The same four major tests were applied-pain, movement, functional activity and the patient's own assessment.

Since excellent function may be maintained in spite of radiographic changes that promise an early deterioration of function, it was considered that some attention had to be paid to the radiograph. For this reason sub-groups were added to the usual classifications of " excellent " and "good" to include those patients with present excellent or good function, but whose prognosis was judged on radiographic evidence to be nevertheless poorer than in the rest of the group. In most patients with excellent function the shape of the femoral head was preserved or restored, but in a few the femoral heads were deformed, there was severe varus or posterior angulation of femoral necks, the joints were narrowed or there was early osteophytic lipping of the joint margins. This discrepancy between radiographic appearance and function has been pointed out by Ratliff (1956).

Shepherd's tests are discussed below in more detail and the summarised system of assessment is shown in Table $I$.

Pain was a common complaint ( 29 per cent), but in only 5 per cent did it interfere in any way with normal activities. In no case was it found to be " disabling" or "crippling "; if it had been so in the past some secondary procedure had ameliorated it before the review.

The mobility index was determined from Gade's (1947) system of grading the various components of hip movement. In this system loss of medial rotation (the commonest residual defect) is not heavily penalised and may even be more than compensated for by the increased range of lateral rotation (Fig. 1). Other imperfections have been described by Jerre (1950) in his detailed monograph.

Gade's indices were calculated to produce an index of 100 for a normal hip, but in the writer's hands the index for fifty normal hips was just over 90 , an indication of the great range of variation in the estimation of hip movements.

When a single hip was affected it was compared to the patient's own normal hip rather than to any arbitrary standard, and was considered to have an excellent range of movement 
if its index differed by no more than five points from that of the unaffected side. When both hips were affected the index for each hip was compared to normal (90); anything within five points of this was considered excellent and within fifteen points good. Other values are shown in Table II.

Assessment by function-Black marks were allotted for selected activities that were difficult or impossible for the patient, and a total score was given. Not as much leeway was allowed for these young, otherwise healthy, people as for the older folk in Shepherd's series, so that

TABLE I

Assessment of Functional Activity

\begin{tabular}{|c|c|c|c|c|c|}
\hline \multicolumn{4}{|c|}{ Activity } & & \multirow{2}{*}{$\begin{array}{c}\begin{array}{c}\text { Black } \\
\text { marks }\end{array} \\
\begin{array}{l}1 \\
0\end{array}\end{array}$} \\
\hline Limp . & . & $\cdot$ & $\cdot$ & $\begin{array}{l}\text { Yes } \\
\text { No }\end{array}$ & \\
\hline \multicolumn{3}{|c|}{ Trendelenburg test } & - & $\begin{array}{l}\text { Positive } \\
\text { Negative }\end{array}$ & $\begin{array}{l}2 \\
0\end{array}$ \\
\hline \multicolumn{3}{|c|}{ Walking outside } & - & $\begin{array}{c}\text { Unaided } \\
\text { Requires one stick } \\
\text { Requires two sticks } \\
\text { Requires two crutches }\end{array}$ & $\begin{array}{l}0 \\
1 \\
3 \\
4\end{array}$ \\
\hline \multicolumn{3}{|c|}{$\begin{array}{l}\text { Distance walked } \\
\text { Completely bedridden }\end{array}$} & . & $\begin{array}{l}\text { Not at all } \\
100 \text { yards } \\
\frac{1}{4} \text { mile } \\
\text { Over a mile }\end{array}$ & $\begin{array}{r}4 \\
3 \\
2 \\
0 \\
10\end{array}$ \\
\hline \multicolumn{4}{|c|}{ Putting on own shoe and sock } & $\begin{array}{c}\text { Yes } \\
\text { With difficulty } \\
\text { No }\end{array}$ & $\begin{array}{l}0 \\
1 \\
2\end{array}$ \\
\hline \multicolumn{2}{|c|}{ Stair climbing } & . & - & $\begin{array}{l}\text { Yes } \\
\text { With difficulty } \\
\text { No }\end{array}$ & $\begin{array}{l}0 \\
1 \\
3\end{array}$ \\
\hline Toilet & . & . & - & $\begin{array}{c}\text { Yes } \\
\text { With difficulty } \\
\text { No }\end{array}$ & $\begin{array}{l}0 \\
1 \\
3\end{array}$ \\
\hline Bathing & . & . & - & $\begin{array}{c}\text { Yes } \\
\text { With difficulty } \\
\text { No }\end{array}$ & $\begin{array}{l}0 \\
1 \\
3\end{array}$ \\
\hline \multicolumn{4}{|c|}{ Work and activities } & $\begin{array}{l}\text { Heavy physical } \\
\text { Moderate } \\
\text { Light } \\
\text { Slight } \\
\text { None }\end{array}$ & $\begin{array}{l}0 \\
1 \\
2 \\
3 \\
4\end{array}$ \\
\hline
\end{tabular}

(Reproduced from Shepherd, M. M. (1954): Assessment of Function after Arthroplasty of the Hip. Journal of Bone and Joint Surgery, 36-B, 354.)

more than one black mark put a patient out of the "excellent" group and no more than three were tolerated for a rating of " good." Table I is reproduced from Shepherd's article and shows how black marks were apportioned.

The patient's own assessment was not a very good yardstick, perhaps because of the optimism of young people. Some patients were uncomplaining about results that by any other standard must be considered poor. The performance of the patients with ankylosed hips testified to the value of an arthrodesis, but an immovable hip must be considered a poor outcome of treatment. 

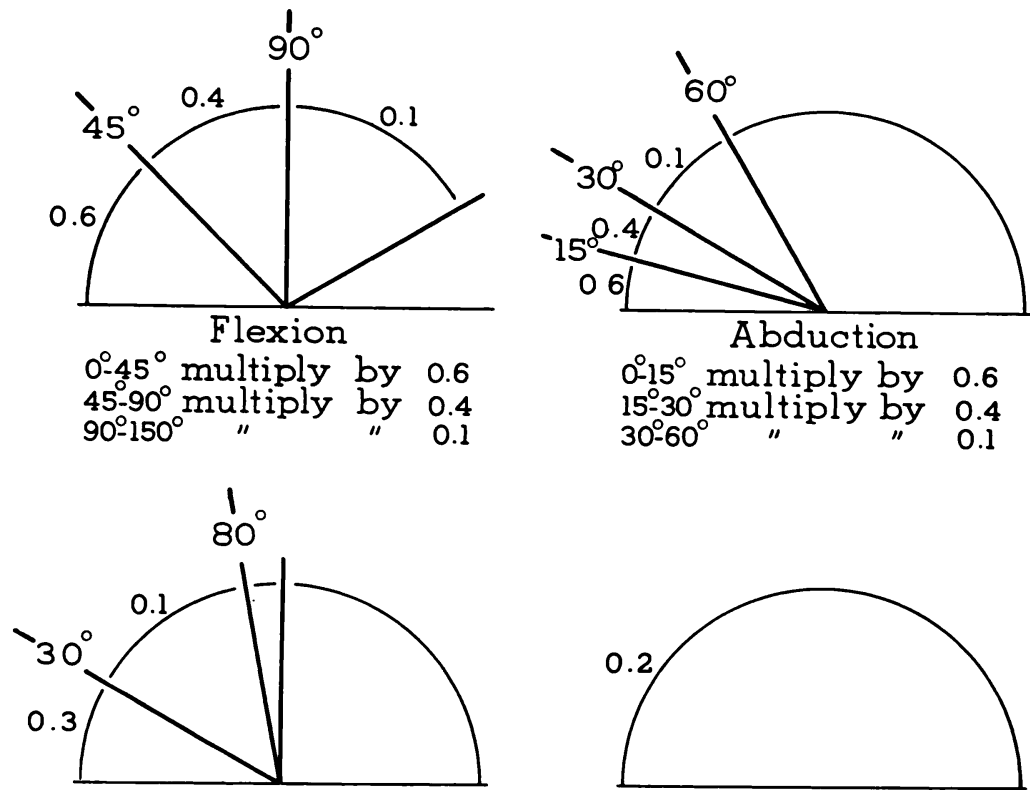

Lateral Rotation

$0^{\circ}-30^{\circ}$ multiply by 0.3 $30^{\circ}-80^{\circ} "$ " 01

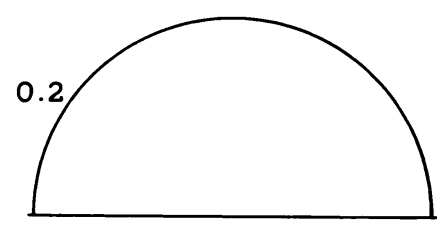

Adduction, Medial

Rotation, Extension multiply by 0.2

Fig. 1

Multiplication factors in Gade's calculation of Mobility Index (from Shepherd, Journal of Bone and Joint Surgery, 36-B, 356). The movements that are most useful for everyday life are most heavily weighted; the first 45 degrees of flexion, 15 degrees of abduction and 30 degrees of lateral rotation are considered to be the most important. A normal hip should have an index of about 100.

TABLE II

Summary of Factors Considered in Arriving at Final Assessment

\begin{tabular}{|c|c|c|c|c|c|c|}
\hline & \multirow{2}{*}{ Pain } & \multicolumn{2}{|c|}{ Mobility index } & \multirow{2}{*}{$\begin{array}{l}\text { Function by } \\
\text { performance }\end{array}$} & \multirow{2}{*}{$\begin{array}{l}\text { Patient's own } \\
\text { assessment }\end{array}$} & \multirow{2}{*}{$\begin{array}{l}\text { Radiographic } \\
\text { evidence }\end{array}$} \\
\hline & & $\begin{array}{l}\text { One hip } \\
\text { affected }\end{array}$ & $\begin{array}{l}\text { Both hips } \\
\text { affected }\end{array}$ & & & \\
\hline Excellent & $\begin{array}{l}\text { "None" } \\
\text { or } \\
\text { "ignores" }\end{array}$ & $\begin{array}{c}\text { Difference of } \\
5 \text { or less } \\
\text { between hips } \\
\end{array}$ & 85 or over & 1 black mark & $\begin{array}{c}\text { "Normal" } \\
\text { or } \\
\text { "very good" }\end{array}$ & \multirow{2}{*}{$\begin{array}{l}\text { Incongruent joint surfaces, } \\
\text { residual gross displacement, } \\
\text { osteoarthritic lipping or } \\
\text { narrow joint space, caused } \\
\text { hip to be placed in sub-group } \\
\text { with poorer prognosis }\end{array}$} \\
\hline Good & $\begin{array}{l}\text { "None" } \\
\text { or } \\
\text { "ignores" }\end{array}$ & $\begin{array}{l}\text { Difference of } \\
6 \text { to } 20 \\
\text { between hips }\end{array}$ & 75 to 85 & $\begin{array}{c}\text { Up to } 3 \\
\text { black marks }\end{array}$ & "Good" & \\
\hline Fair & $\begin{array}{c}\text { Makes } \\
\text { concessions }\end{array}$ & $\begin{array}{l}\text { Difference of } \\
21 \text { to } 40 \\
\text { between hips }\end{array}$ & 50 to 75 & $\begin{array}{c}\text { Up to } 5 \\
\text { black marks }\end{array}$ & $\begin{array}{l}\text { Gives some } \\
\text { trouble }\end{array}$ & \\
\hline Poor & $\begin{array}{l}\text { Disabling } \\
\text { or } \\
\text { crippling }\end{array}$ & $\begin{array}{c}\text { Difference of } \\
40 \text { or over } \\
\text { between hips }\end{array}$ & less than 50 & $\begin{array}{c}6 \text { or more } \\
\text { black marks }\end{array}$ & "No good" & \\
\hline
\end{tabular}

The result was recorded in the lowest category indicated by any single factor. Fair and poor results were almost always associated with radiographic evidence of gross deformity. 


\section{CHARACTERISTICS OF THE SERIES}

Of the 138 patients examined, thirty-five were found to have both hips affected ( 25.4 per cent), making a total of 173 hips to be reported. There was a slight preponderance of males (54.3 per cent), and among the males a definite predilection for the left hip in unilateral cases (thirty-nine left $v$. seventeen right). This preference for the left hip was not apparent among the female group (twenty-five left $v$. twenty-two right). The significance, if any, of this finding is not known (Table III).

TABLE III

Side Affected in Relation to Sex

\begin{tabular}{|c|c|c|c|c|c|c|c|}
\hline \multicolumn{4}{|c|}{ Male } & \multicolumn{4}{|c|}{ Female } \\
\hline Unila & ateral & \multicolumn{2}{|c|}{ Bilateral } & \multicolumn{2}{|c|}{ Unilateral } & \multicolumn{2}{|c|}{ Bilateral } \\
\hline Right side & Left side & Right side first & Left side first & Right side & Left side & Right side first & Left side first \\
\hline 17 & 39 & 12 & 7 & 22 & 25 & 10 & 6 \\
\hline
\end{tabular}

The average duration of observation was eighty-six months, ranging from three months to forty-three years; 82.8 per cent of the patients were seen four years or more after the beginning of their treatment.

Although this is not an etiological study the case histories of two patients are of some interest in relation to the question of whether an acute slip occurs in a previously normal epiphysis.

Case 55 (Mr R. N. Traquair's patient) - A boy aged fifteen and a half years who had complained of pain in his right hip for eight weeks, was sent for radiography. After the antero-posterior film had been taken his hip was flexed and abducted for the lateral picture. This manoeuvre caused severe sudden pain. The antero-posterior film showed a minimal slip, and subsequent films showed a complete one.

Case 100 (Mr H. P. Hall's patient) - A girl aged twelve and a half years having limped for three weeks had an antero-posterior radiograph taken. While leaving the $\mathrm{x}$-ray room she tripped and fell. As in the previous case, the first film showed a minimal slip, subsequent films a complete one. It is suggested that whether the onset shall be gradual or acute is a matter of chance.

TABLE IV

RESULTS

\begin{tabular}{|c|c|c|}
\hline Category & $\begin{array}{l}\text { Percentage } \\
\text { of cases }\end{array}$ & Remarks \\
\hline Excellent & $48 \cdot 3$ & $\begin{array}{l}1 \text { in } 12 \text { were considered on } \\
\text { radiographic evidence to have } \\
\text { a less than excellent prognosis }\end{array}$ \\
\hline Good & $29 \cdot 6$ & $\begin{array}{l}1 \text { in } 5 \text { had radiographs indicat- } \\
\text { ing an unfavourable prognosis }\end{array}$ \\
\hline Fair & 6.9 & \\
\hline Poor & $15 \cdot 2$ & \\
\hline
\end{tabular}

\section{RESULTS OF VARIOUS TREATMENTS}

By the criteria set out in Table II the results fell into the groups shown in Table IV.

The difficulties in assessment were legion, partly because the work of a great many surgeons is represented, each doing something just a little different. The patient was often 
subjected to more than one type of treatment (for instance, a period of traction followed by a manipulation and an operation), so that it was difficult to judge the contribution of each to success or failure. Notes were often inadequate and the patient's recollection was seldom precise, so that conflicting accounts of the type of onset were not rare.

To facilitate discussion and comparison, the series has been broken down into several broad groups. The results obtained in these groups have been summarised in Table $\mathrm{V}$ and will be discussed more fully below.

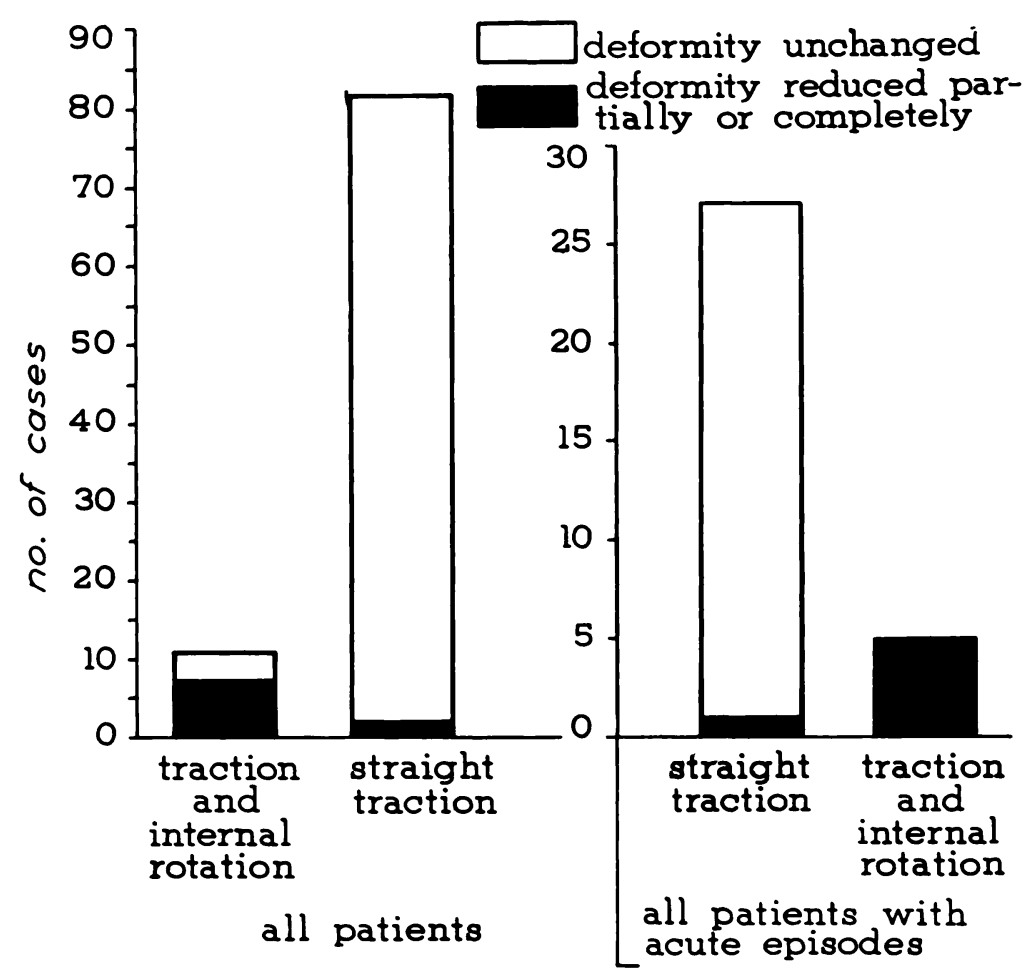

FIG. 2

A composite chart showing the value of medial rotation combined with traction. The left side of the chart shows that much greater success follows the use of medial rotation with traction than the use of traction alone. On the right side of the chart the patients who had histories of acute episodes are segregated. It can be seen that this group contains six of the nine patients in whom the displacement was successfully reduced. All five patients with acute episodes who were treated by traction plus medial rotation had their deformities reduced.

\section{NON-OPERATIVE TREATMENT}

Non-operative treatment included among other things traction in recumbency, immobilisation in a plaster spica, the use of a weight-relieving caliper, or just simple rest in bed. The results then depended on the initial degree of displacement, because it was not usually changed by these methods.

Three types of non-operative treatment did make some difference; these were manipulation, traction combined with medial rotation, and forced abduction on a frame.

Forced abduction was used on five occasions on hips that could not be passively abducted. Avascular necrosis followed in three of these, with a poor result in a fourth.

Traction was the most commonly used form of treatment, being recorded in ninety-two cases, either as the definitive treatment or as a preliminary to some other method. Since serial radiographs were usually taken of patients treated by traction, it was evidently hoped 
that it would lead to a diminution in the displacement. This hope was realised in just under 10 per cent of cases. Two factors were found to be of paramount importance: 1) whether or not medial rotation was used; and 2) the type of onset.

The most common residual deformity, as well as one of the earliest signs of this disease, is a limitation of medial rotation. This suggests how the deformity is produced and that attempted reduction should include some method of applying medial rotation.

In only eleven instances out of the ninety-two was specific mention made of medial torsion as part of the traction apparatus, and in seven of those the deformity was partly or

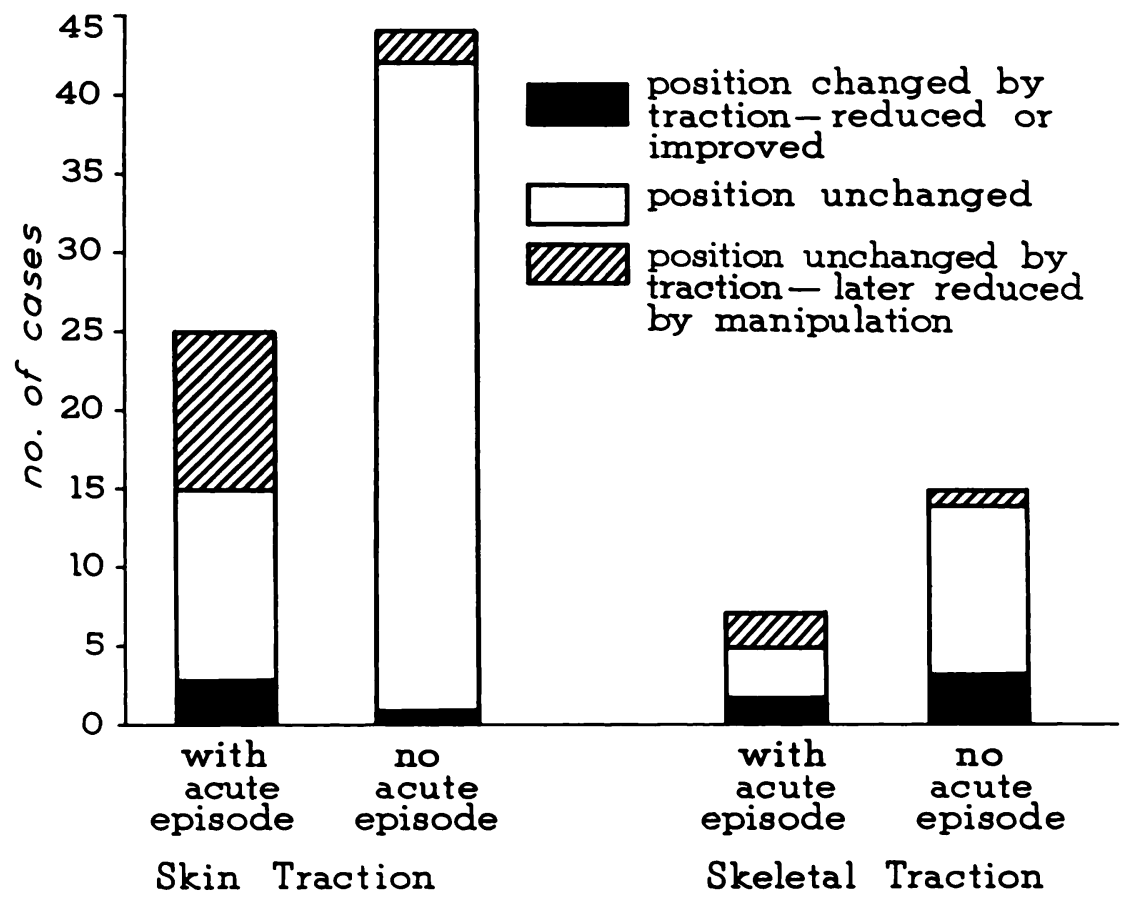

Fig. 3

The efficacy of traction in reducing deformity. Skin and skeletal traction are compared, and the importance of the history of an acute episode is shown. Patients with an acute episode treated by skin traction seldom had any change in their deformity, but subsequent manipulation was often successful. In patients who had no acute episode, neither traction nor manipulation had any great success. Skeletal traction was slightly more successful but the same principle holds.

completely reduced. Of the other eighty-one, presumably treated by straight longitudinal traction alone, the deformity was reduced in only two (Fig. 2). Perkins (1932) found that straight traction alone would reduce the deformity in early cases of sudden onset.

A factor that seems important in determining the possibility of closed reduction is the history of a recent acute episode (Foley 1946, Vaughan-Jackson 1956). To be significant, this episode should have been severe enough to prevent walking for several days. Such was the case in thirty-two patients treated by traction begun a few hours to several weeks after the episode. Twenty-seven of these were treated by straight traction, with success in only one case. The other five were treated by traction combined with medial rotation for one or two days, and in all five the deformity was reduced partly or completely (Fig. 2). Of the sixty patients who gave no history of acute episodes, traction changed the displacement in three.

Skeletal traction, employed seventeen times, succeeded slightly better than skin traction 
in reducing displacement. The Steinmann pins, whether in the lower end of the femur or in the upper end of the tibia, did no harm; the range of knee movement was diminished in three cases only, by 10 degrees or less.

Figure 3 is a composite chart showing the relative effectiveness of skin and skeletal traction, and also showing that manipulation was used to reduce the deformity after traction had failed in fifteen cases.

Manipulation under a general anaesthetic was recorded in thirty-three cases, either as part of non-operative treatment or as a prelude to operation. Some success in changing the

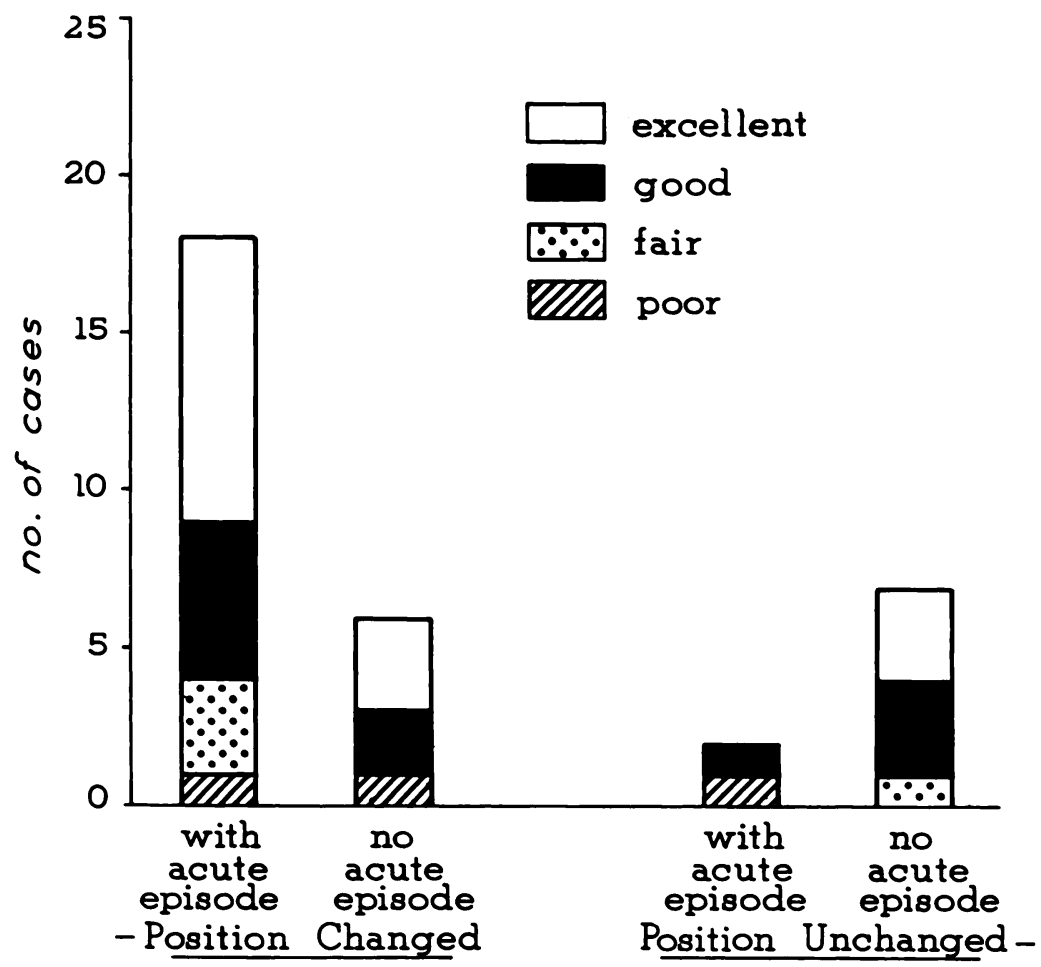

Fig. 4

Results of treatment by manipulation. This table shows that most patients whose deformities were reduced by manipulation had acute episodes in their history. Of the patients whose deformity was unchanged, only a small proportion had had an acute episode. The table shows also that a good proportion of satisfactory results can follow manipulation done in the right type of patient.

relationship of the epiphysis to the metaphysis was obtained in twenty-four hips, and no change could be detected in the other nine.

The manipulation consisted in strong medial rotation applied with longitudinal traction. This was accompanied in several instances by forced abduction, and there is some evidence that this is not only unnecessary but may be harmful to the epiphysial blood supply.

Patients with a recent acute episode had the best prospect of epiphysial reduction by manipulation. Of the nine in whom this failed, only two had had acute episodes, and these had occurred more than a month before. Eighteen of the twenty-four in whom manipulative replacement had been achieved had reported an acute onset or an acute episode after a period of minor hip disability.

Kleinberg and Buchman (1936) condemned manipulation even in recent cases with an acute onset, stating that avascular necrosis was the usual sequel.

VOL. 39 B, NO. 4, NOVEMBER 1957 
Subsequent epiphysial avascular necrosis was observed in three cases of successful reduction. In two there had been no acute episode. A Smith-Petersen nail was used in one of these and in the third case.

In two cases in which the manipulation was unsuccessful the epiphysis underwent avascular necrosis.

Twenty of the patients treated by manipulation had suffered a recent acute episode, and in eighteen of them the manipulation was partly or completely successful in reducing the deformity.

Thus it seemed that a firm gentle manipulation was a relatively safe and effective way of reducing the displacement in a case seen within a few weeks of an acute episode.

These findings are summarised in Figure 4, which shows the results obtained after successful and unsuccessful manipulation in patients with or without an acute episode.

\section{OPERATIVE TREATMENT}

Smith-Petersen nails or other large trifin nails were used on eighty-four occasions, thirty-six times after cervical osteotomy and forty-eight times either as primary treatment or after a period of traction or a manipulation.

The results were generally satisfactory, but complications were found in a surprisingly large number of patients.

Avascular necrosis-In the cases of nailing without any direct attack on the femoral neck there were five examples of avascular necrosis. Brief case reports on the patients are as follows.

Case 5A-A boy aged fifteen years at onset in August 1953 had complained of pain in his right knee and of a limp for five months. The pain became worse in December 1953 after a fall, and in January 1954 a Smith-Petersen nail was inserted. No mention was made of a manipulation in the operation note, but some change was noted in the position by radiography after operation. Avascular necrosis was noticed two months later, beginning in the segment near the tip of the nail. An arthrodesis was performed in April 1955.

Case 18-A boy aged fourteen in October 1950 sustained in an accident a left femoral supracondylar fracture and a completely separated upper epiphysis. With ten days' skin traction this was reduced. A Smith-Petersen nail was inserted and weight bearing was begun after fourteen weeks. He had no complaint until January 1953 when his left hip became painful. A radiograph revealed avascular necrosis, and a cup arthroplasty was performed in June 1953. In October 1955 the cup was removed and the head and neck of the left femur were excised, leaving a mobile, painless, reasonably stable hip. It is possible that this case represents a fracture-separation of the femoral epiphysis.

Case 38B-A boy aged sixteen at onset in October 1949 noticed pain in both hips while running for a bus. Radiographs showed a severe slip of the right femoral epiphysis with a minimal slip on the opposite side. He was placed on an abduction frame for ten weeks. In February 1950 a cervical wedge osteotomy was performed on the right side with Moore's pins for internal fixation. In March 1950 a simple nailing with a Smith-Petersen nail was done on the left hip. Both epiphyses subsequently became avascular, and in retrospect it could be seen that the joint spaces were narrow before operation. Virtually all hip joint movement was lost on both sides, and cup arthroplasties were done, neither of which was successful.

Case 49-A boy aged fifteen suffered in October 1951 a complete sudden slip which was treated by a manipulation and Smith-Petersen nailing. Avascular necrosis followed. A cup arthroplasty in October 1952 was not successful; and an arthrodesis was performed in May 1954.

Case 120B-A girl aged thirteen suffered minimal slipping of the right femoral epiphysis in February 1949. A Smith-Petersen nail was inserted. In August 1950 she suffered a sudden complete slip on the left side, which was treated by a manipulation and Smith-Petersen nail. Radiographs at three months were suggestive of avascular necrosis, and weight bearing was deferred for two years until there was evidence of revascularisation. The functional result is now good.

It may be noticed that in each of these cases some other factor must share responsibility with the Smith-Petersen nail. It may be that the added trauma of driving a large nail into the femoral head may be enough to abolish completely an already precarious blood supply (Howorth 1949, Jerre 1950). Possibly the blood supply of an epiphysis that could survive 
either a manipulation or a Smith-Petersen nailing would occasionally find the combination lethal. Such was the case in three of the eight patients in whom this combination was used. With this in mind, Cleveland, Bosworth, Daly and Hess (1951) suggested a delay between reduction and fixation.

Subtrochanteric fracture through the cortex penetrated by the Smith-Petersen nail (Klein, Joplin, Reidy and Hanelin 1953) had occurred in three cases. This complication happened with trivial injury between one and two months after a seemingly uneventful operation. In one case the nail was removed and the limb immobilised in plaster; in the other two the nail was replaced by a nail and plate. One of these was further complicated by fracture of the plate and non-union of the bone, but union was eventually secured by the use of a Küntscher nail and bone graft. The final result was excellent in all three.

Crack fracture of the femoral neck was produced at two operations but healed rapidly with no residual disturbance.

Gap between epiphysis and metaphysis-Radiographs after operation showed that the epiphysis had been driven about one-eighth of an inch away from the metaphysis in two patients, but in each the gap gradually filled with new bone and there was no evidence of disturbance of epiphysial blood supply.

TABLE V

Results According to TyPe OF TREATMent

\begin{tabular}{|c|c|c|c|c|c|}
\hline & $\begin{array}{c}\text { Total } \\
\text { number }\end{array}$ & Excellent & Good & Fair & Poor \\
\hline Non-operative: no manipulation & 32 & $43.8 \%$ & $34.4 \%$ & $6 \cdot 3 \%$ & $15.6 \%$ \\
\hline Non operative: with manipulation & 11 & $27 \cdot 2 \%$ & $45.4 \%$ & $18.2 \%$ & $9 \cdot 1 \%$ \\
\hline Smith-Petersen nail & 48 & $68.9 \%$ & $18.8 \%$ & $4 \cdot 2 \%$ & $8.4 \%$ \\
\hline Moore's pins & 20 & $80 \%$ & $20 \%$ & - & - \\
\hline Cervical osteotomy & 42 & $23.7 \%$ & $35 \cdot 7 \%$ & $4 \cdot 7 \%$ & $35.8 \%$ \\
\hline Subtrochanteric osteotomy & 9 & $22 \cdot 2 \%$ & $33 \cdot 3 \%$ & $22 \cdot 2 \%$ & $22 \cdot 2 \%$ \\
\hline Bone graft on anterior epiphysial line & $3^{*}$ & $100 \%$ & - & - & - \\
\hline No treatment & 9 & $33 \cdot 3 \%$ & $44.5 \%$ & $22 \cdot 2 \%$ & - \\
\hline
\end{tabular}

* One of these continued to slip three months after operation and was further treated by Moore's pins-final result was excellent.

Moore's pins (Moore 1935) or other slender multiple pins were just as effective as SmithPetersen nails in preventing slipping or maintaining reduction, and their use was seldom followed by complications (Blount 1945, Howorth 1949). They were employed twenty times, with no complication except erosion of two pins. In one case in which two non-threaded pins were inserted they backed out within four months of the operation, but no further slipping was noticed in spite of continued weight bearing. Table $\mathrm{V}$, which shows only excellent and good results after pinning with Moore's pins, indicates a clear-cut seeming superiority of the small pins over Smith-Petersen nails. However, the patients treated with Moore's pins were under observation for an average of only 21.6 months, compared with 67.7 months for those treated with Smith-Petersen nails. It may be that avascular necrosis will eventually be evident in some of these patients, eight of whom had had successful manipulations.

When the position of the epiphysis has been changed by traction, manipulation or open reduction, there was general agreement that no weight should be borne on the hip for at least three months. Early weight bearing, within two weeks of the operation, was allowed in 
eighteen patients after a minor degree of slipping had been accepted and fixed in situ by Moore's pins or a Smith-Petersen nail. In no case was there any cause for regret: an excellent result was found in twelve, and a good result in the other six.

Cervical osteotomy-This operation was recorded forty-two times. It was performed in a variety of ways by many different surgeons. The cases have been grouped according to the site and type of osteotomy and on the type of fixation. Figure 5 represents the results in each group. The number is rather small for hard-and-fast conclusions but some general ones are apparent. Contrary to some early reports (Whitman 1909, Key 1926), cervical osteotomy without internal fixation was almost uniformly disastrous. Avascular necrosis seemed to be least common after low cervical wedge osteotomy, in spite of good reports of the wedge at

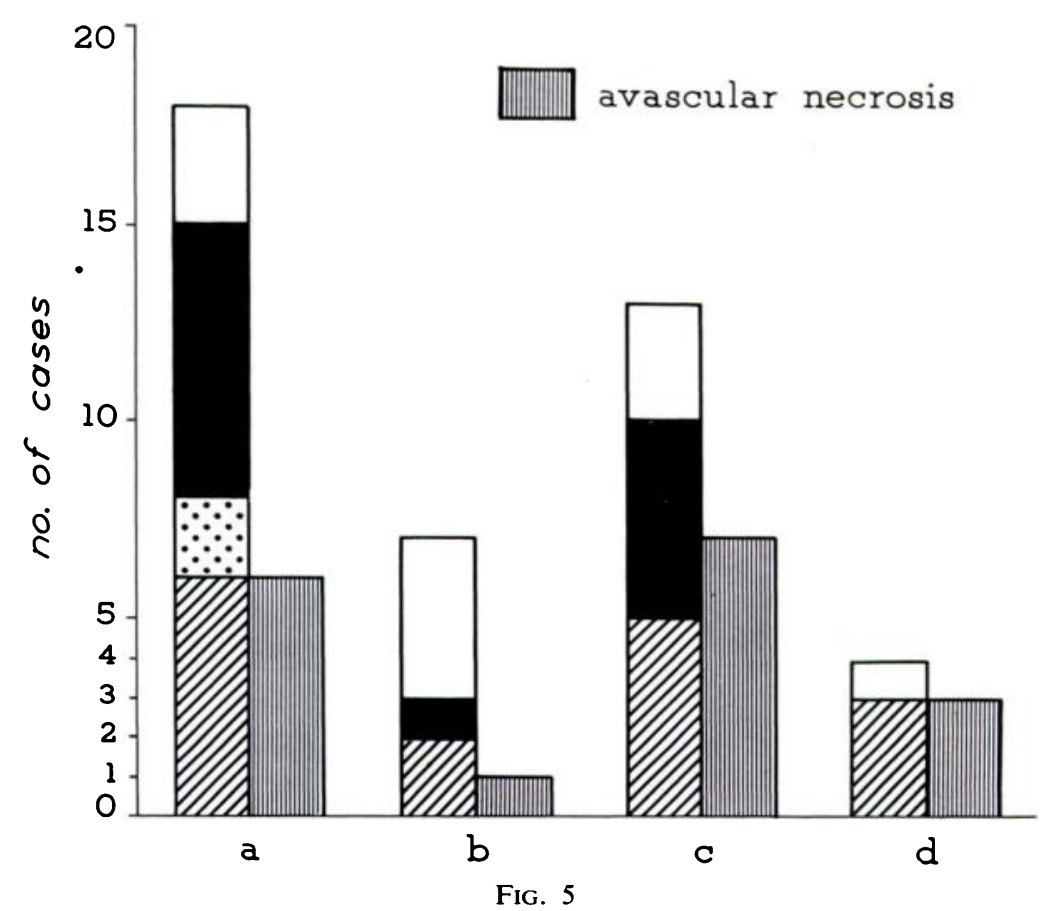

Results of different types of cervical osteotomy. The same key as in Figure 4 has been used to show the proportion of Excellent, Good, Fair and Poor results. Group a-Osteotomy at the epiphysial line, with removal of a wedge of metaphysis: internal fixation with a Smith-Petersen nail. Avascular necrosis in $33 \cdot 3$ per cent. Group b-Wedge osteotomy low in the neck: internal fixation with a Smith-Petersen nail. Avascular necrosis in $\mathbf{1 4 . 3}$ per cent. Group c-Curved osteotomy at the epiphysial line but no wedge of bone was removed: fixation with Smith-Petersen nail, lag screw, bone peg or Moore's pins. Avascular necrosis in 53.8 per cent. Group d-Any type of cervical osteotomy, with or without removal of a wedge of bone: no internal fixation. Avascular necrosis in 75 per cent.

the epiphysial line (Kleinberg and Buchman 1936, Foley 1946, Martin 1948, Compere 1950, Cleveland et al. 1951, Klein et al. 1953).

A Smith-Petersen nail was used for internal fixation in thirty-six of the forty-two operations, and one cannot but wonder whether avascular necrosis ( 38.1 per cent) would have been any less common if some type of smaller pin had been used.

It is worth noting that three patients who showed radiographic evidence of avascular necrosis, and were kept off weight bearing for two years, now have hips that are regarded as excellent in one case and good in the other two.

Intertrochanteric osteotomy was employed nine times, usually when the epiphysis was solidly fused in the deformed position. The usual method of fixation was a plaster spica, but in the 
one case in which internal fixation was used, with a nail and plate, the result almost qualified as excellent. The only poor result was in a case complicated by avascular necrosis. As there had been an unsuccessful manipulation before operation, it is difficult to incriminate the osteotomy.

Perkins (1932) advocated subtrochanteric osteotomy for late cases and those with a gradual onset; and lately there has been a revival of interest in this operation. Good results with little danger of avascular necrosis are reported.

Bone grafts across the epiphysial line (Howorth 1949) were used in three patients, who were confined to bed for three months after operation. Two had no further trouble. The third patient continued to have pain on weight bearing, and further slipping was demonstrated by radiography. Internal fixation with Moore's pins ended her symptoms, and all three patients had excellent final results.

Negligible treatment-Nine patients whose present radiographs show unmistakable evidence of a previous slipped femoral epiphysis in the reputedly normal side had no treatment for it, except bed rest while the opposite hip was treated. Most of them could not recollect any

TABLE VI

InCIDENCE OF Avascular Necrosis

\begin{tabular}{|c|c|c|}
\hline \multicolumn{2}{|l|}{ Treatment } & $\begin{array}{l}\text { Percentage with } \\
\text { avascular } \\
\text { necrosis }\end{array}$ \\
\hline Cervical osteotomies-all types . & . & $38 \cdot 1$ \\
\hline Smith-Petersen nail plus manipulation & . & $37 \cdot 5$ \\
\hline Non-operative treatment without mani & ation . & $12 \cdot 5$ \\
\hline Subtrochanteric osteotomy* & . & $10 \cdot 9$ \\
\hline Non-operative treatment including a $\mathrm{m}$ & pulation & $9 \cdot 1$ \\
\hline Smith-Petersen nail without a manipula & . & $5 \cdot 0$ \\
\hline Moore's pins with or without a manip & ion & 0 \\
\hline
\end{tabular}

* This represents one patient who underwent unsuccessful manipulation before operation.

Avascular necrosis occurred in 18.3 per cent of all patients subjected to manipulation.

pain in the neglected hip. The present condition is shown in Table $\mathbf{V}$; in general the result depended on the degree of displacement. It is interesting to speculate how many of the distorted osteoarthritic hips seen in older patients had their origin in unrecognised slipped femoral epiphyses.

Salvage operations were necessary in eleven patients, usually when the initial treatment ended in avascular necrosis. Four arthrodeses, four cup arthroplasties and three displacement osteotomies were done. The cup arthroplasties all failed; the arthrodeses, two of which had to be repeated, gave very good results.

\section{FACTORS MODIFYING RESULTS}

Avascular necrosis influenced the end result more than any other single factor. Of the twentyseven patients with poor results, twenty had been victims of avascular necrosis. A poor result was not inevitable after loss of epiphysial blood supply, but was usual. The total number of examples of avascular necrosis was twenty-seven, an incidence of 15.6 per cent, and the result in all but seven of them was rated as poor. Of the other seven, the result in 
three was fair, in three good, and in one excellent. One of those rated as good had radiographic evidence of an incongruous joint, but in the rest the joint looked practically normal. The patients with excellent and good results had all been treated by non-weight-bearing for about two years.

As Waldenström (1930) and more recently Moore (1945) and Jerre (1950) have suggested, avascular necrosis seemed to appear in two forms. In a minority of cases not only does the bony epiphysis lose its blood supply but there is also a massive necrosis of articular cartilage. The joint space is visibly narrowed before other radiological changes are evident, and the range of movement is seriously restricted. Eventually the joint space is completely lost, and the result is an ankylosed hip. In the other type, although the joint space may be decreased,

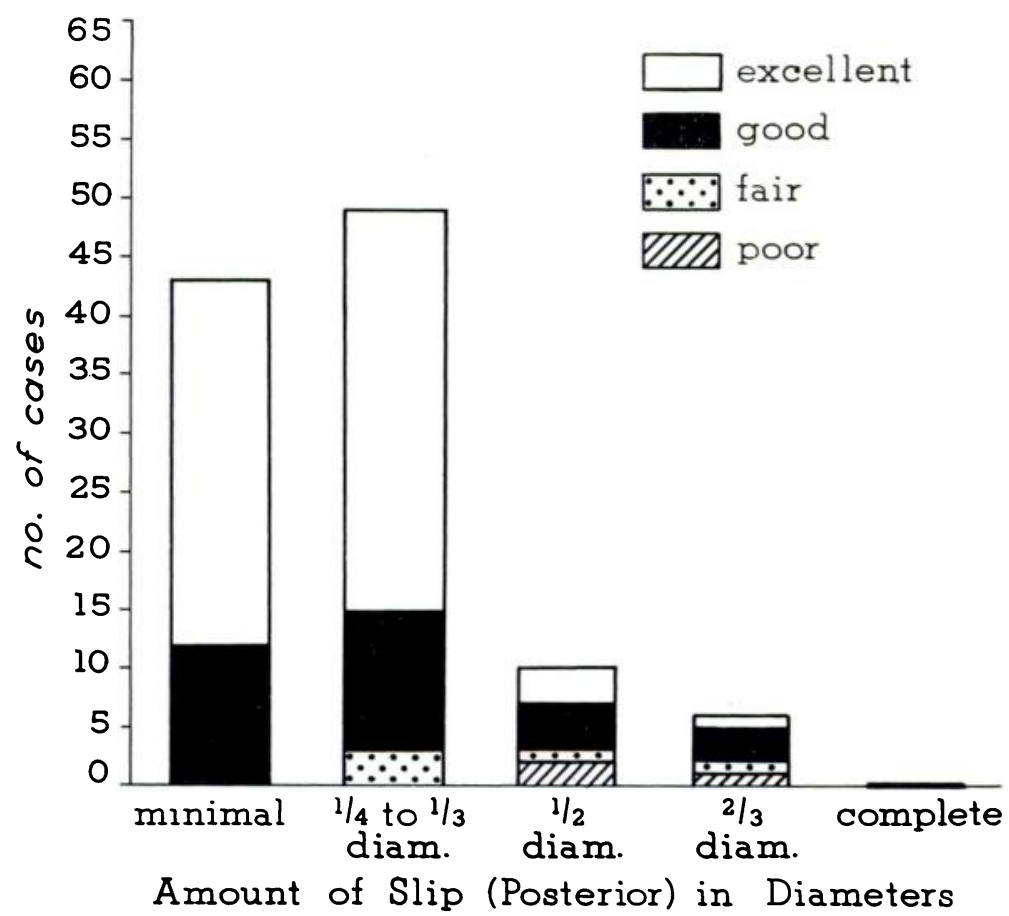

Fig. 6

Results classified by extent of displacement accepted or achieved by closed methods. The only cases not included are those treated by cervical or subtrochanteric osteotomy. If a manipulation was performed the final position is indicated. In a large proportion internal fixation was carried out by a Smith-Petersen nail or Moore's pins. A significant observation is the large percentage of satisfactory results even when a final displacement of one-half or even two-thirds diameter is accepted or obtained. It is doubtful whether so many would be found to be so good when they have reached their fifties.

the principal change is confined to the bony epiphysis and the chance of retaining a useful range of movement is much greater.

Three instances of the former type were seen, two of them in one patient who was kept recumbent on an abduction frame for ten weeks. At the end of this time, both joint spaces were narrow and hip movements were seriously diminished. Subsequent operations on both hips ended in disaster.

Cervical osteotomies were a potent source of avascular necrosis with an incidence of 38.1 per cent. Following closely behind, with 37 per cent, were cases treated by combined manipulation and insertion of a Smith-Petersen nail. Smith-Petersen nailing without previous manipulation carried with it a 5 per cent chance of avascular necrosis. 


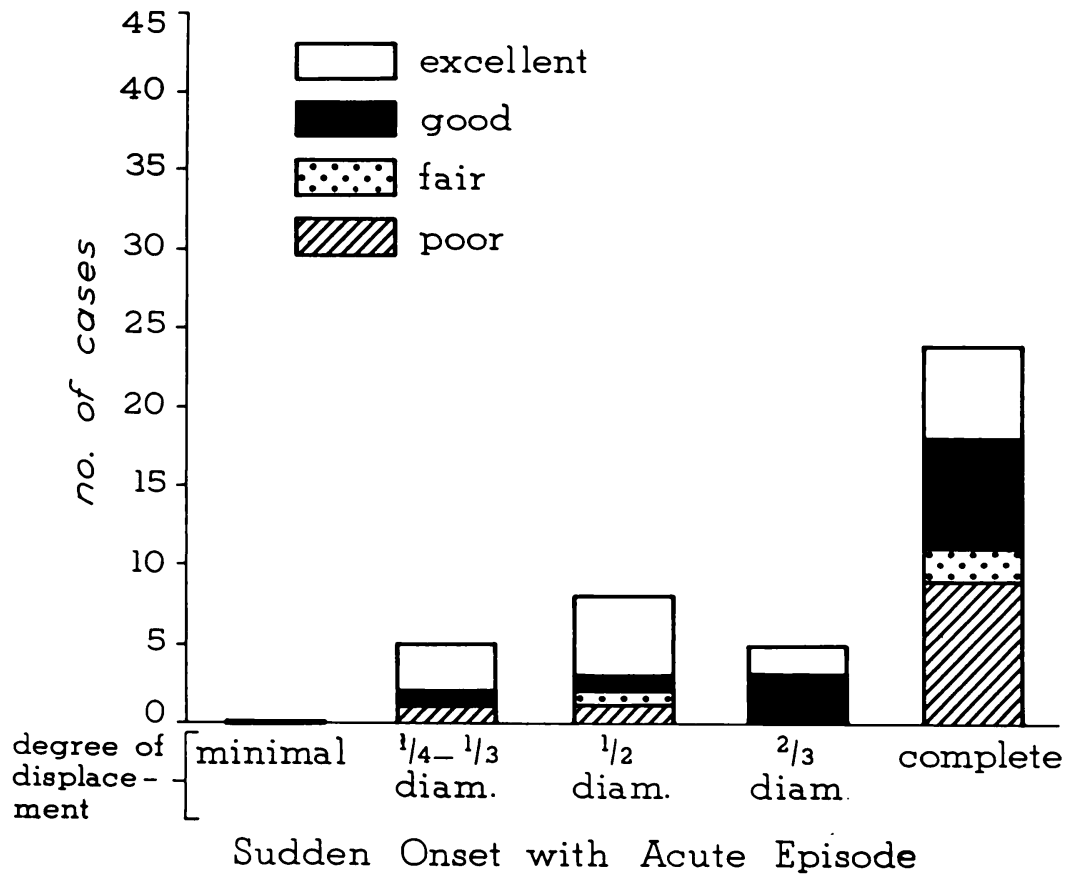

FIG. 7

Results in patients with an acute onset according to the extent of displacement when first seen. Displacement tended to be greater if the onset were acute. The results were unsatisfactory in a large proportion of cases with complete displacement. In this group the results tended to be better in patients seen early and treated by manipulation than in those subjected to cervical osteotomy.

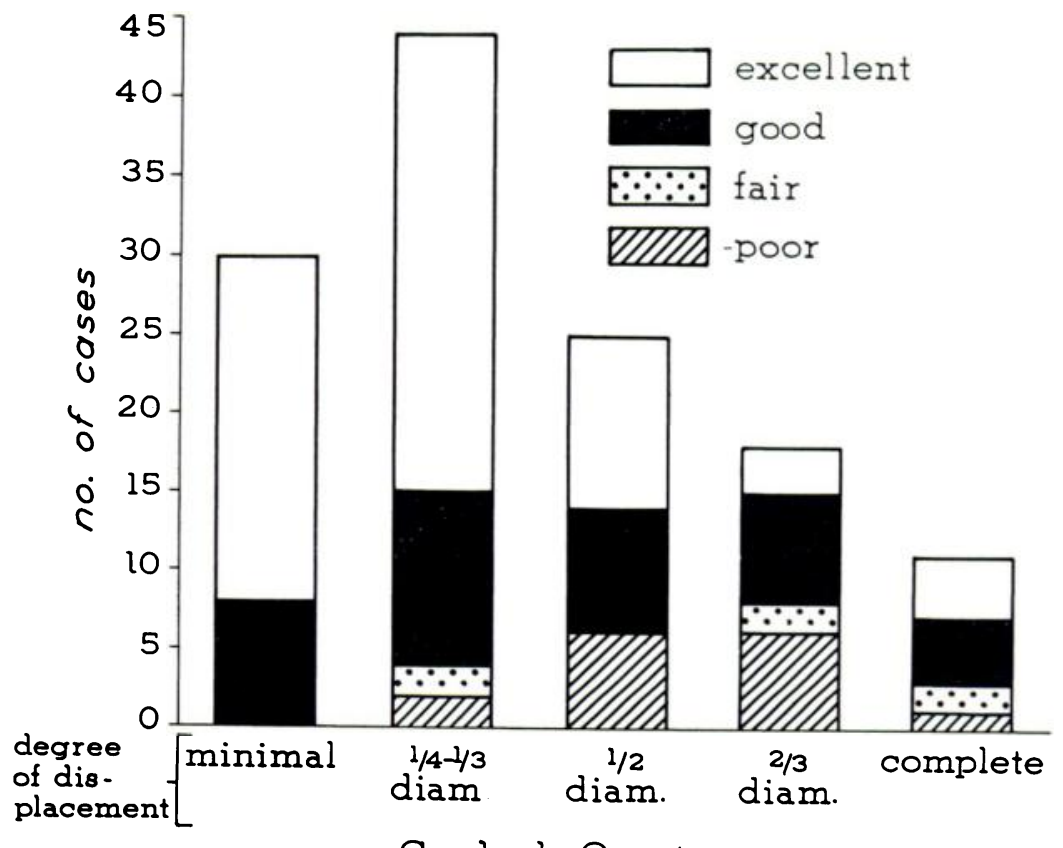

\section{Gradual Onset}

Fig. 8

The results in patients with a gradual onset according to the extent of displacement when first seen. Smaller degrees of displacement were more common with a gradual onset than with a sudden one, and the results were almost uniformly satisfactory. Complete displacements nearly always led to cervical osteotomies, and the results were better than in the group with an acute onset.

VOL. 39 B. NO. 4, NOVEMBER 1957 
Previous mention has been made that no instance of avascular necrosis has been seen after manipulation and the insertion of Moore's pins, but the duration of observation is short. Table VI correlates this complication with the type of treatment.

Final displacement-The extent of displacement that was accepted or finally obtained had some influence on the result. Numerous attempts were made to establish some accurate method of measuring degrees of displacement, but no constant relationships could be found. The method of estimating the amount of slip in relation to the diameter of the head was favoured. This review confirms the usual assertion that a slip of one-quarter or even one-third of the diameter of the head as seen in the lateral view can be accepted. Figure 6 even suggests that about the same result was obtained by accepting a slip of one-half diameter as by performing a cervical osteotomy.

Type of onset-In Figures 7 and 8 an attempt has been made to correlate the type of onset and the initial extent of displacement with the result obtained. A gradual onset was found to be more common than a sudden one, and those with a sudden onset tended to present a greater displacement when first seen. As might be expected, the best results followed a gradual onset and minor slipping.

Delay in treatment was important because it allowed greater slipping and forced the surgeons to employ more hazardous forms of treatment. There was a noticeable trend towards earlier diagnosis in the more recent cases.

\section{SUMMARY AND CONCLUSIONS}

1. One hundred and seventy-three hips in $\mathbf{1 3 8}$ patients have been examined and studied in reference to the type of treatment received.

2. Shepherd's method of assessing the results of arthroplasty operations has been adapted to this series.

3. Satisfactory results were found in $\mathbf{7 7 . 9}$ per cent of all patients.

4. The value of straight longitudinal traction is questioned. Medial rotation appears to be an essential step in the reduction of the deformity.

5. Manipulation was found to be a relatively safe and effective method of reducing the deformity in patients seen soon after an acute episode, and should be reserved for them.

6. Complications were common after nailing operations, and included subtrochanteric fracture in three cases.

7. Avascular necrosis was the commonest cause of a poor result. The two types of avascular necrosis are discussed.

8. Avascular necrosis was found in 37 per cent of cases in which a manipulation was followed by a nailing operation.

9. Avascular necrosis was not found in any case in which a manipulation was combined with the use of Moore's pins, but such cases were kept under observation for a shorter time.

10. Avascular necrosis was found in $38 \cdot 1$ per cent of cases of cervical osteotomy.

I would like to thank all of the surgeons who have allowed me to see their patients and who have made my visits to their hospitals so pleasant and instructive.

Particular thanks are due to Mr H. Jackson Burrows and Mr H. J. Seddon, who have made this work possible, and Mr P. H. Newman, Mr E. N. Wardle and Dr W. R. Harris for their helpful advice and encouragement.

I am also grateful for the valuable aid of the staff of the Records Office of the Royal National Orthopaedic Hospital; of Miss M. Bayer, Orthopaedic Secretary; and of Miss Titus of the Medical Art Department of the University of Toronto.

This work was carried out under a grant provided by the Board of Governors of the Royal National Orthopaedic Hospital.

Thirty-four of these patients were examined for Mr P. H. Newman by the writer as an outside assessor and have been reported before by Mr Newman at the meeting of the British Orthopaedic Association in May 1956. 


\section{REFERENCES}

Badgley, C. E., Isaacson, A. S., Wolgamot, J. C., and Miller, J. W. (1948): Operative Therapy for Slipped Upper Femoral Epiphysis. An End Result Study. Journal of Bone and Joint Surgery, 30-A, 19.

Blount, W. P. (1945): Discussion following Paper by Green, W. T., on Slipping of the Upper Femoral Epiphysis. Archives of Surgery, 50, 32.

Burrows, H. J. (1957): Slipped Upper Femoral Epiphysis. Characteristics of a Hundred Cases. Journal of Bone and Joint Surgery, 39-B, 641.

Cleveland, M., Bosworth, D. M., Daly, J. N., and Hess, W. E. (1951): Study of Displaced Capital Femoral Epiphyses. Journal of Bone and Joint Surgery, 33-A, 955.

COMPERE, C. L. (1950): Correction of Deformity and Prevention of Aseptic Necrosis in Late Cases of Slipped Femoral Epiphysis. Journal of Bone and Joint Surgery, 32-A, 351.

Foley, W. B. (1946): Treatment of Slipped Upper Femoral Epiphysis. Proceedings of the Royal Society of Medicine (Section of Orthopaedics), 39, 201.

GADE, H. G. (1947): A Contribution to the Surgical Treatment of Osteoarthritis of the Hip-Joint. A Clinical Study. Acta Chirurgica Scandinavica, 95, Supplementum 120.

Ghormley, R. K., and FaIRChiLD, R. D. (1940): The Diagnosis and Treatment of Slipped Epiphyses. Journal of the American Medical Association, 114, 229.

Green, W. T. (1945): Slipping of the Upper Femoral Epiphysis. Diagnostic and Therapeutic Considerations. Archives of Surgery, 50, 19.

Howorth, M. B. (1949): Slipping of the Upper Femoral Epiphysis. Journal of Bone and Joint Surgery, 31-A, 734.

Jerre, T. (1950): A Study in Slipped Upper Femoral Epiphysis. Acta Orthopaedica Scandinavica, Supplementum 6.

KeY, J. A. (1926): Epiphyseal Coxa Vara or Displacement of the Capital Epiphysis of the Femur in Adolescence. Journal of Bone and Joint Surgery, 8, 53.

Klein, A., Joplin, R. J., Reidy, J. A., and Hanelin, J. (1953): Slipped Capital Femoral Epiphysis. Springfield, Illinois: Charles C. Thomas.

Kleinberg, S., and Buchman, J. (1936): The Operative Versus the Manipulative Treatment of Slipped Femoral Epiphysis with a Description of a Curative Operation. Journal of the American Medical Association, 107, 1,545. Martin, P. H. (1948): Slipped Epiphysis in the Adolescent Hip. A Reconsideration of Open Reduction. Journal of Bone and Joint Surgery, 30-A, 9.

Moore, A. T. (1935): Fracture of the Hip Joint-A New Method of Treatment. International Surgical Digest, 19, 323.

MoOre, R. D. (1945): Aseptic Necrosis of the Capital Femoral Epiphysis Following Adolescent Epiphyseolysis. Surgery, Gynecology and Obstetrics, 80, 199.

Perkins, G. (1932): Treatment of Adolescent Coxa Vara. British Medical Journal, i, 55.

Raturf, A. H. C. (1956): Pseudocoxalgia. Journal of Bone and Joint Surgery, 38-B, 498.

SHEPHERD, M. M. (1954): Assessment of Function after Arthroplasty of the Hip. Journal of Bone and Joint Surgery, 36-B, 354.

Vaughan-Jackson, O. J. (1956): Reducibility of Slipped Femoral Capital Epiphyses. Proceedings of the Royal Society of Medicine (Section of Orthopaedics), 49, 812.

Waldenström, H. (1930): On Necrosis of the Joint Cartilage by Epiphyseolysis Capitis Femoris. Acta Chirurgica Scandinavica, 67, 936.

Whitman, R. (1909): Further Observations on Injuries of the Ncck of the Femur in Early Life. Medical Record, 75, 1.

Wilson, P. D. (1924): Displacement of Upper Epiphysis of Femur Treated by Open Reduction. Journal of the American Medical Association, 83, 1,749.

Wilson, P. D. (1936): Conclusions Regarding the Treatment of Slipping of the Upper Femoral Epiphysis. Surgical Clinics of North America, 16, 733. 